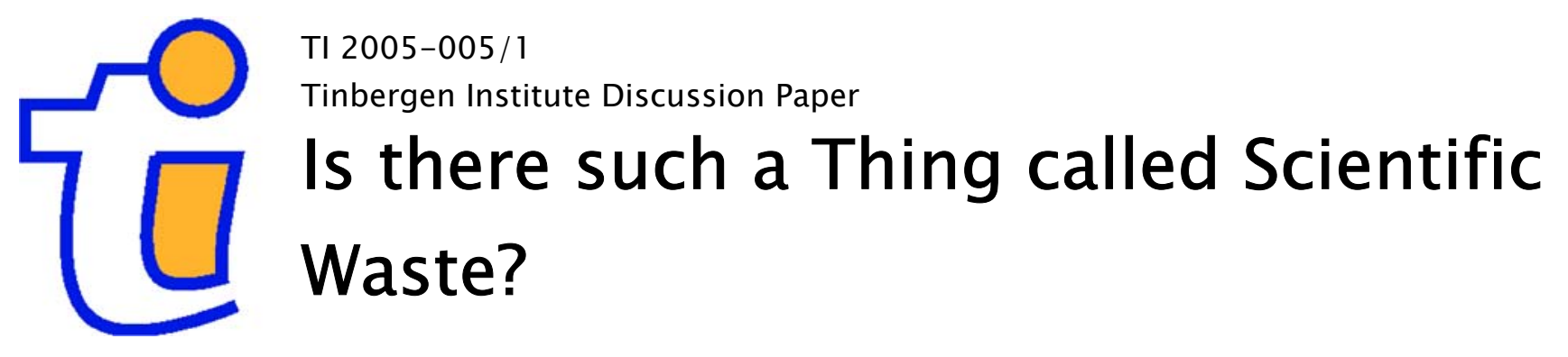

Hendrik P. van Dalen'

Arjo Klamer ${ }^{2}$

'Department of Economics, Erasmus Universiteit Rotterdam, Tinbergen Institute, and Netherlands Interdisciplinary Institute NIDI, The Hague,

2 Department of History and Arts, Erasmus Universiteit Rotterdam. 
Tinbergen Institute

The Tinbergen Institute is the institute for economic research of the Erasmus Universiteit Rotterdam, Universiteit van Amsterdam, and Vrije Universiteit Amsterdam.

Tinbergen Institute Amsterdam

Roetersstraat 31

1018 WB Amsterdam

The Netherlands

Tel.: $\quad+31(0) 205513500$

Fax: $\quad+31(0) 205513555$

Tinbergen Institute Rotterdam

Burg. Oudlaan 50

3062 PA Amsterdam

The Netherlands

Tel.: $\quad+31(0) 104088900$

Fax: $\quad+31(0) 104089031$

Please send questions and/or remarks of nonscientific nature to driessen@tinbergen.nl.

Most TI discussion papers can be downloaded at http://www.tinbergen.nl. 


\title{
Is There Such a Thing Called Scientific Waste?
}

\author{
Hendrik P. van Dalen* and Arjo Klamer**
}

January 4, 2005

* Erasmus University Rotterdam

Department of Economics and Tinbergen Institute

P.O. Box 1738

NL-3000 DR Rotterdam

The Netherlands

Netherlands Interdisciplinary Demographic Institute

P.O. Box 11650

NL-2502 AR The Hague

The Netherlands

Email: dalen@nidi.nl

** Erasmus University Rotterdam

Department of History and Arts

P.O. Box 1738

NL-3000 DR Rotterdam

The Netherlands

www.klamer.nl

JEL codes: A14, H4, O34

Key words: science, public good, citations

Abstract:

Science is a winner-take-all profession in which only few contributions get excessive attention and the large majority of papers remains receives scant or no attention. This so-called 'waste' together with all the competitive strategies of scientists seeking attention is part and parcel of any creative profession and not a worrisome fact as the price society pays for human ingenuity is extremely small: 0.0006 percent of world income goes into the publication of scientific research. The more worrisome features of competition in academic economics reveal themselves not through ordinary citation or publication statistics or competitive attention seeking strategies. The badly designed use of market principles in which citations and publications have become the sole measuring rod of scientific 'productivity' deserve more attention instead of the excessive focus of attention on uncitedness as such. 


\section{Introduction}

In 1991 the journal Science made the headlines with a bibliometric exercise that suggested the wastefulness of scientific research. ${ }^{1}$ It showed that about half the science papers was never cited within the 5 years time span after publication, a result that spurred Newsweek to conclude that "nearly half the scientific work in this country is worthless" and to depict "scientists with their belief in their God-given right to tax-payer dollars" as "welfare queens in white coats." (April 2, 1991) Later on the figures were corrected for some anomalies but the blow to the outside world stood. ${ }^{2}$ The suspicion of waste in scientific research was affirmed. Recently, Laband and Tollison (2003) have done a similar exercise for the economics profession and they show that, in spite of the growth of resources between 1974 and 1996 invested in academic research, the percentage of uncited papers in economics has remained more or less constant at 26 percent. In their view this is evidence of scientific waste or 'dry holes' as they dub them. "Scholarly economic research presents many of the characteristics of a rent-seeking game (p. 168)," was their conclusion.

Laband and Tollison are, of course, not the only ones to worry about the value of scientific research. ${ }^{3}$ Scientists experience this supposed wastefulness of their practice in the battle for attention. They know how difficult it is to get their research published, and even more difficult to get it published in a good journal; and they know that even when a paper gets published, the chance of it getting read and cited is pretty slim. Scientists may want to believe that they are making claims to the truth, but the truth is that those claims often go unnoticed. It is an iron law that most articles receive few or no citations and only a few articles receive a great many (Klamer and Van Dalen, 2002). This law is the frustration of practicing scientists and may come as a shock to those interested in and funding scientific research. But before concluding that scientific research involves a great deal of waste or that doing science is senseless if the work is not noticed, we may want to reconsider the practice of science to understand why this so-called waste occurs. It may be inevitable. And it may well be that the real waste shows up in a different guise, which citation and publication data will not easily detect.

\footnotetext{
${ }^{1}$ See Hamilton $(1990,1991)$.

${ }^{2}$ Later on the ISI by means of a letter by David Pendlebury in Science (March 22, 1991) corrected these figures, as the initial figures included journal marginalia (book reviews, letters, editorials). The corrected uncitedness figures for physical sciences are $22 \%$ (initially $47 \%$ ), social sciences $48 \%$ (initially $75 \%$ ) and the humanities 93\% (initially $98 \%$ ).

${ }^{3}$ Mayer (2004) shows some of the pitfalls of citation statistics as arranged by Laband and Tollison.
} 


\section{Some Facts of 'Waste'}

So how bad is the state of the scientific publication industry? What are the facts? The outstanding feature of scientific publication and citation behavior is the skewness, not only in publication productivity of scientists, but in particular the citations these publications and their authors receive: most articles receive few or no citations and a few receive a great many. The median article in a science journal has a negligible influence on the literature, only the top 5 or 10 percent of the science literature matters, i.e. it gets read and is cited by peers. Generally these top journals represent the core of a discipline; journals which have a wide circulation, extensive peer review and are managed by people who have made their mark and who can recognize high quality or high impact papers (although their choices are, of course, not flawless). The type of skewness may be a sign of competitiveness within a science: the more skewed the distribution of attention is the larger the pay-off to risky research and in that respect Table 1 gives us a flavor of the differences among sciences.

Competition in the natural sciences is not only revealed by the number of journals and articles appearing, the core journals in the sciences also take up a larger share of the ongoing conversation, even more so if you correct for the impact which the average article in journals have had for the past two years. E.g., the top 10 percent of highly cited medicine journals produce 27 percent of all the articles in the medicine profession and if you correct for the impact of these articles the top 10-percent of medicine articles accounts for 75 percent of the 'conversation' in this discipline.

The differences across disciplines are to a degree the reflection of different citation practices: medicine and psychology journals are far more efficient in handling manuscripts than most social science journals (Elison, 2002a, 2002b). By shortening turnaround times from submission to date of publication one can establish that the immediacy of impact is larger. These differences notwithstanding, the skewness of the distribution of citations is a fact for all of them; and each discipline knows the phenomena of large share of the published papers that get never cited.

However, the conclusion that all the uncited work is 'waste' and therefore should not be funded is unwarranted. It is as misguided as the conclusion that most of the play during a football game is waste because it does not produce a score. Imagine that the players would have to limit themselves to playing the highlights only! Movie producers cannot limit themselves to the production of blockbusters. Apparently, scores and hits have to occur in the company of many hapless moments and efforts, such as uncited and unsuccessful research. 
Table 1: Size and distribution of publications in a number of sciences and social sciences, 2002*

\begin{tabular}{lcccc}
\hline Discipline & \#journals & $\begin{array}{c}\text { \# articles published } \\
\text { in journals }\end{array}$ & $\begin{array}{c}\% \text { articles published by } \\
\text { top-10\% journals }{ }^{\mathrm{a}}\end{array}$ & $\begin{array}{c}\text { Idem \% articles } \\
\text { published in top-10\% } \\
\text { journals weighted by } \\
\text { impact factor }\end{array}$ \\
\hline Science & 5,876 & 716,304 & 30.3 & 51.8 \\
Biology/biotechnology & 193 & 18,279 & 40.4 & 64.0 \\
Chemistry & 418 & 85,530 & 30.0 & 50.6 \\
Computer Science & 338 & 19,739 & 22.5 & 33.4 \\
Mathematics & 329 & 22,998 & 26.7 & 74.5 \\
Medicine & 183 & 20,883 & 46.9 & 69.6 \\
Physics & 267 & 85,718 & & 41.4 \\
Social Sciences & 1,709 & 64,039 & 28.3 & 24.8 \\
Anthropology & 53 & 1,491 & 9.3 & 29.1 \\
Economics & 166 & 7,081 & 12.0 & 33.5 \\
Educational research & 116 & 3,572 & 12.3 & 28.1 \\
Law & 102 & 2,719 & 14.5 & 56.4 \\
Political Science & 80 & 2,995 & 28.3 & 45.9 \\
Psychiatry & 78 & 4,735 & 27.1 & 33.7 \\
Psychology & 422 & 16,759 & 13.2 & \\
Sociology & 93 & 2,550 & & \\
\hline & & & & \\
\hline
\end{tabular}

* There is some overlap between the journals of the sciences and the social sciences and the disciplines within these sciences hence the total number of journals of the ISI database is smaller than the sum of science and social science journals.

(a) Selection of the top 10 percent of the journals is based on total number of citations received by a journal in the year 2002.

Source: Institute for Scientific Information, 2003, Journal Citation Reports, as reported in Web of Science, Philadelphia.

The discussion may improve if the participants were to understand the skewed distribution of citations. ${ }^{4}$ Here is a likely explanation. The extreme skewed distribution of citations, we argue, is part and parcel of what we will call the attention game in science (Klamer and Van Dalen, 2002). Science is a creative profession in which all participants both look for attention,

\footnotetext{
4 An extra reason why differences in citation rates and levels of uncitedness between sciences exist is the difference in citation practices. It takes, for instance, far more years before a publication is recognized in the social sciences such as sociology and economics, than an idea is recognized in medicine or chemistry (cf. Hargens, 2000, and Van Dalen and Henkens, 2004).
} 
for their work that is, and need to pay attention to the work of others (to keep up with what is going on). The problem is the excess: there are far too many articles for any scientist to pay attention to, let alone to read. The Renaissance scholar, who covered a great variety of fields, is inconceivable nowadays. Everybody has to make a selection and will usually follow others in doing so. (We leave out the screening that takes place before publication; that process only amplifies the skewed outcome). One scientist reads an article because others cite it; by citing it in her own work, others may turn to the article as well. And so the snowball continues squashing all kinds of other articles on its path. This outcome of the attention game reflects what the sociologist of science Robert Merton has called the Matthew effect of science-- those who have will receive -and is consistent with what economists depict as a winner-take-all profession (Frank and Cook, 1995). As in the attention games in the movie and book publishing industries as well as in the arts, the amount of attention paid to scientific work and recognition received is highly skewed towards the 'lucky' few. The superstars receive excessive attention whereas the starlets and the rank-and-file receive little or none.

In view of the odds, participation in this attention game is a gamble: the risk is great that one's work goes unnoticed and uncited yet if one article happens to catch the attention, the rewards in terms of reputation, invitations to conferences and possibly promotion are great. The speculative character of the game continues to affect even the stars. They may continue to publish but continued attention after a hit is far from guaranteed. You would say that they are guaranteed ample attention but even they run the risk to have their work ignored. Nobel prizes are usually awarded for work done early in the career. The critic might argue that funding should be halted after that first success, as the chance at another success is small; the remainder of the work is waste. Yet, who will tell? Like the dull moments in a game, 'waste' is an inevitable part of creative work. Eliminate waste and you eliminate the chance at the rare outstanding work.

Skewness implies the phenomenon of stars. We know from the economics of superstars (Rosen, 1981) that superstars are characterized by (1) a close connection between personal reward and the size of one's own market; and (2), a strong tendency for both market size and reward to be skewed toward the most talented people in the activity. Large markets are like science prizes; they stimulate the search for new territory. Social scientists like sociolo gists and economists have to be satisfied with far smaller markets than people working in chemistry and physics, and therefore are engaged as much in priority races. In physics and medicine priority in discovery is on every scientist's mind because the prize of recognition is large. 


\section{The Cost of a Common Good - Science}

The infatuation with citation figures of deans and policy makers and the concomitant question of why so many articles are never cited will remain at the forefront of the policy debate as the flood of publications will increase in the age of electronic publishing and therewith the number of anonymous authors who fail to catch a glimmer of the limelight. Policymakers tend to turn skeptical when they find out about this so-called waste in scientific research. Why should they allocate scarce tax dollars to finance such a waste? But the costs of such a waste is minimal especially when we consider that scientific research is in principle a game without geographical borders: After all, most of the research gets communicated in international journals with English as the lingua franca. Science is therefore not a national but a global affair. Stiglitz (1999) has stated more than once that research produced by scientists is a global public good and should also be treated as such. Whether this argument will help to win votes for the budgets of national science foundations is questionable, but it helps us putting the publishing game in the appropriate perspective.

To make our case let's assume that there is one gigantic decision maker who finances research and who is quite sympathetic to the scientist's fate and who couldn't care less whether the publications produced by the numerous scientists are cited or not. Sooner or later ideas will pop up and among those ideas there will be an excellent idea that saves costs, lives or time to calculate another excellent idea. The only concern this decision maker has is that ideas are produced, communicated and brought out in the open as soon as possible. That is the entire idea of the publishing game in science. It is a tournament in which being the first to publish a report is the scientist's only prize worth having, in return society receives knowledge. Now what should this publishing game cost the average tax payer: 10 percent of national income, 1 percent, 1/1000 of a percentage point or even less than this small fraction? Applying some back-of-the-envelope accounting one can easily show that the publishing game is not at all a worrisome institution. For purposes of making this numerical claim we will define scientific research as all knowledge codified and disclosed in journals registered by the ISI in the science citation index (SCI) and the Social Science Citation Index (SSCI). The cost of producing one article covers a large number of inputs, like the monetary value of time it takes the author to produce a paper, the time editors and referees put into evaluating the merit of publishing the paper and then there are the costs the publisher has to incur like printing, copy-editing, marketing and last but not least the mark-up to make publishing a profitable business. The direct costs incurred by publishing firms and reflected in serial prices attract the most attention in discussions on the serial crisis or the publishing crisis. Estimates 
of direct costs based on a sample of mathematics and engineering journals fall in the range of $\$ 1000$ to $\$ 8000$ per article. But direct costs are by and large dwarfed by the indirect costs of which the costs of preparing a paper must surely be the largest category. Tentative estimates arrive at the amount of $\$ 32,000$ per article of which $\$ 20,000$ is imputed to the author's cost of preparing a paper, $\$ 8,000$ for library costs and $\$ 4,000$ for editorial and refereeing costs (Odlyzko, 1997). The total number of articles published in the 7,500 research journals in the sciences and social sciences amounts to 762,000 multiplied by the all inclusive cost per article of $\$ 40,000$ - taking the most conservative estimate of the direct costs into account - and one arrives at the grand total bill of codified science of $\$ 30.5$ billion. To keep in line with the earlier arrived principle that science is a global affair one should relate this number to the world income and in doing so the publishing game of science seems to be a cheap affair as 0.0006 percent of world income of 2002 (48,443 billion US\$ at purchasing power parities, source IMF) is allocated on making scientific knowledge public.

Sure enough, the ISI journals are only the tip of the iceberg of science journals: according to Ulrich's International Serials Database there are currently (issue 2004) about 250,000 journals being published of which 21,000 are refereed. If we take the latter group as the boundary set and we assume that these journals publish more or less the same amount of articles as the journals registered by ISI then we should multiply the science cost figure by a factor 2.8. In other words, the corrected price of publishing scientific findings is 0.0018 percent of world GDP. That makes science not an entirely free lunch, but it certainly is a cheap lunch.

\section{Competitive strategies of attention seekers}

Even if the supposed waste of scientific research does not add up to large monetary amounts, practicing scientists continue to have to live with the harsh facts of the attention game in which they are involved. 'How to survive in the game and emerge with some recognition?' seems to be on the mind of every modern-day scholar. Edward Leamer (1981) gives us a hint of what kind of strategies scientists could follow or actually do follow to gain attention.

\footnotetext{
"Many of you will conjure up reasons why the number of citations should be ignored. There are fads; there are self-citations; there are conspiracies; there are derogatory citations; there are bribes to editors and referees; there are sycophantic students; and there are subjects capable of direct understanding by only a few. But why didn't your paper start fads; why don't you publish more and cite yourself; why did your conspiracies fail; why don't you become an editor; why don't your students care about your welfare; and why don't you insist on writing about obscure issues?"
} 
The ultimate question is of course: do these strategies distort the conversation in science in a significant manner or is this simply the way the world of science works and it may well be working fine? Let's consider the most important strategies that Leamer cites and evaluate their alleged distortionary nature for a science that is close to home: economics.

\section{Starting fads}

Starting a fad is much frowned upon by academics, but let's face it, it involves a special talent to make a subject the 'talk of the town'. Stigler (1955: 6) also considers this possibility and points out that a fad will only make "a deep and lasting impression on the science if the idea meets the durable standards of the science." To make an idea stick it is not sufficient to be original, salesmanship has to accompany the process of invention. Stigler takes the case of John Stuart Mill as exemplary for an original mind who did not sell his ideas persuasively or accompany his written thoughts by salesmanship and for that reason has not become truly path-breaking.

The most common strategy to gain attention from peers and get the ball rolling is simply by 'advertising'. In writing on the technique of persuasion George Stigler (1955) states that new ideas are even harder to than new products: "Wares must be shouted - the human mind is not a divining rod that quivers over truth." General repetition, inflated claims and disproportionate emphases are according to Stigler the strategies that accompany the adoption of every new idea in economic theory. The techniques of persuasion have not lost their touch as Figure 1 below shows: in trying to attract attention to papers in the economics literature: in trying to rise above the enormity of papers being published an increasing number of economists grabs the browsers attention by promising new paradigms, new theories or new perspectives in the title of their paper. Over the years, there have been apparently more breakthroughs or more paradigm shifts in economics than philosophers ever could have imagined. Of course, such claims are inflated ${ }^{5}$ and scientific practice corrected for such inflation behaves far less progressive than the attention grabbing words suggest.

\footnotetext{
5 See for an earlier evaluation of the use of inflated claims Cohen (1999), who notices that 90 percent of the 'new paradigm' papers affect the research world very little.
} 
Figure 1: Inflated claims - attention grabbing title words in economic literature, 19692003

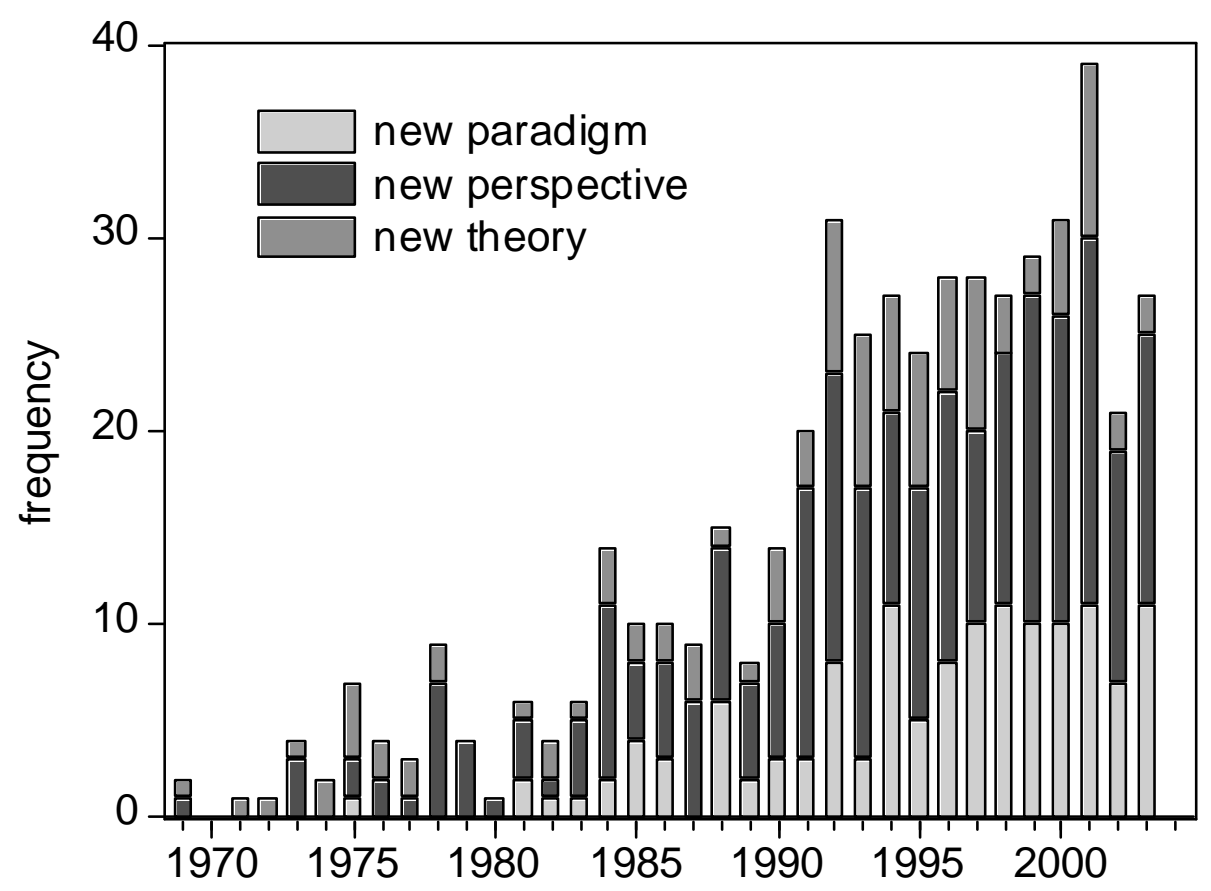

Source: Econlit (2004)

Salesmanship is just as important in grabbing attention as the scientific quality of a work. In that respect scientists can learn a bit from ordinary businessmen who value both Research and Development whereas scientists give the impression that the $\mathrm{R}$ of research is all that matters. The tenacity of door-to-door salesman has to be part of the make-up of a scientist and advertising for your own work (by self-citation, by brainwashing your students or by organising workshops and conferences) are legitimate efforts. The scholar who successfully sells his or her ideas is in the words of Stigler "more a warrior against ignorance than a scholar among ideas." According to the Institute for Scientific Information approximately 20 percent of all citations are self-citations.

Publish, publish...or perish

One condition of getting recognized is the academic status of the researcher. Hundred years ago, and back, men of practical affairs who were almost on an equal footing with academic scholars when it came to publishing research (Stigler et al., 1995). Their articles appeared regularly in the academic journals. Nowadays, academic credentials are a prerequisite for the right to get published in an academic journal. Gentlemen researchers do not stand a chance in 
the current game for attention. Even academics that venture out in the non-academic world, like in the government bureaucracy or in a research department of a private organization see their chances for academic publication seriously diminish. Publications of non-academically occupied economists in star journals like the American Economic Review are rare, whereas in the distant past the appearance of practitioners was more common phenomenon. The dominant player in the production of ideas is the Academic Professional (Klamer and Colander, 1990). Graduate training tells the students that the only chance they have to make it in the academic attention game is an academic job at a top university. As an Academic Professional their lives will focus on academic life with its academic conferences, research seminars, socializing with other academics, and endless hours in the office. Such life does not guarantee citations but it is the only chance.

Late bloomers make little chance in this game. Educational institutions put a premium on relatively early manifestations of ability. In making decisions on who is to become a member universities are increasingly relying on publication and citation records (Hargens and Schuman, 1990) and indicators of future productivity, such as the time required for completing the doctorate. Merton (1988: 614) may warn against the pitfalls of such a practice, but academic institutions do not want to take chances with the late bloomers.

Graduate students adopt the behaviour of their teachers. Zuckerman (1977) shows in her survey of US Nobel laureates how students of eminent and prolific scientists in general are also prolific writers. Graduate training generally proves to be decisive for the novice academic professional. As Buchmüller et al. (1999) demonstrate publications and submissions prior to leaving graduate school increase the probability of being employed at a research university where productivity is higher. And so the ball starts rolling. The question of course, is whether this character trait is acquired or already apparent and merely cultivated by the supervisor. According to Van Ours and Ridder (2003) who examined the PhD completion records of Dutch graduates in economics, the research productivity of the supervisor is an important determinant of completion and dropout rates of graduates. However, the apparent effect of the research track record of supervisors on the completion rates is due to the selection or attraction of high ability students and not to superior supervision.

\section{'Conspiracy' - create your own club}

The most enduring strategy to make the process of gaining, distributing and sharing attention manageable is to create clusters. Scientists specialise and form clusters in their specialisation, 
each with its own 'discursive practice' or 'conversation', its own journal and association and annual conference. Clustering is a condition for making the process of attention seeking and getting more manageable. The downsizing of clusters has proven to be an effective response to the inflation of research publications. It enables all kinds of selection procedures without which the world of science would not be able to function. The connection with the phenomenon of 'stars' is obvious. We suspect that the larger the cluster, the more space there is, and need, for the creation of stars, charismatic leaders who bring order out of chaos. The reason may be that sustenance of the large cluster (say econometrics or finance) requires a core knowledge that all 'members' share. The sharing will force a highly skewed distribution of attention. Indeed, anyone who has seen his or her share of rankings knows that people like Clive Granger or Eugene Fama are in far better position to generate a huge amount of citations with a single article than economists working in some esoteric sub-discipline.

The idea that clusters of scientists are important for the transmission and generation of ideas goes back to Crane's concept of invisible colleges that dominate the frontiers of science (Crane, 1972). Ideas do not consistently come out of the blue, i.e. ideas are not randomly scattered around the world. Geographic proximity of great minds matters in the birth of ideas. This is clearly illustrated in the dominance of a few institutions that have attracted Nobel laureates, the University of Chicago being of course the champion attractor of Nobel economists (see Van Dalen,1999). The main importance of clusters is that they set the standard of conversation, they frame the questions of interest, select the conversation or sparring partners and they test the robustness of ideas in debate. Naturally it is of some importance to win a debate because influencing one big giant is worth far more at the invention stage than influencing ten dwarfs who may perhaps give you their promise they will cite you but whose papers rarely get published and certainly not in core journals. Or look at it in another way: not only do giants generally form a better testing ground they are also prolific writers of high impact articles in which they cite the proposed idea. To see how this works out in practice take a look at Figure 2 which illustrates the 'applause' generated by Paul Romer's article on "Increasing Returns and Long-Run Growth" in the Journal of Political Economy of 1986. Romer had just finished his $\mathrm{PhD}$ thesis and this article was his very first article. A striking characteristic of the total number of citations is that increasing returns applies not only to the content of the article but very much to the attention generated for a very long stretch in the lifetime of this particular article. Ten years after the publication date the number of citations settle at around 118. However, the most striking aspect of the attention generated by Romer is to be found in the role played by economists belonging to the core or their 
profession and the core journals. The first three to four years after the publication of the JPE article the core economists and core journals generate almost single-handedly the attention, after six or seven years the economists publishing in second tier journals take over, which is also not so difficult to understand: not only did these second-tier economists had to forego the first-mover advantage which the 'invisible college' economists had, they are generally not so prolific and skilled in getting papers published. When the followers catch on, the innovators in the publication process have already moved on and lost interest in the initial paper, in the last three years a meagre 5 percent of the citations to the Romer-paper come from top economists, in contrast to the very beginning of the paper's career when 90 percent of the citations were generated by the 'core' economists.

Figure 2: Citations generated by Romer's Increasing Return Article, 1986-2000

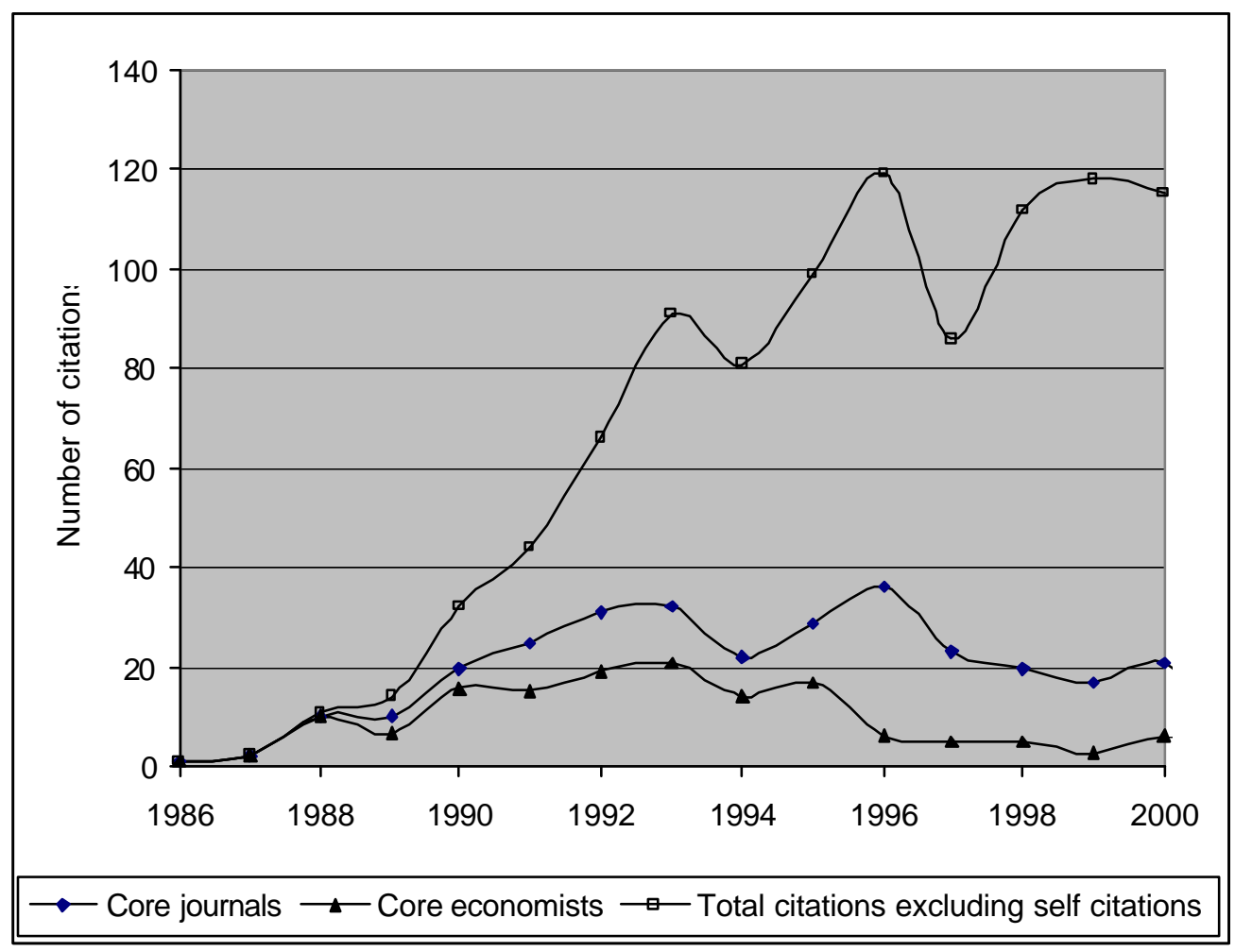




\section{Searching for the real 'waste'}

Starting fads, publish or perish and starting your own club are strategies that are 'all in the game'. Economics teaches us that there is always another side to a story. Economics is about trade-offs and seeking attention relentlessly by each and every one participant has its price. The strategy of Stigler to advertise with the zest of a used-car salesman has the drawback that words loose their meaning, or to rephrase this for the subject at hand: Inflated claims inflate your reputation and your ideas. But.... as rational expectations teaches us that we can (in principle) see through the veil of money we should also be able to see through inflated claims. However, just like money illusion exists in everyday life we have to doubt the ability of participants to see through the veil of the academic coin. Inflated claims in science will thereby affect real behaviour of the community of scientists. This is perhaps seen in its most eminent form in the work of new classical economists. A telling anecdote is perhaps the following made by Robert Lucas (2001). He and his co-author Leonard Rapping were joking at a social occasion about a remark made by Edmund Phelps in the introduction to the book Microeconomic Foundations of Employment and Inflation Theory. Phelps stated that “.... perhaps Lucas and Rapping are 180 degrees to the truth.", and Lucas and Rapping, being young academics and elated for being cited for the first time in an important volume, found this an amusing statement. However, Rapping's wife who was also present when they chuckled over Phelps' remark, was shocked and said:

\footnotetext{
"All you two care about is being cited by a well-known economist, about being famous. It doesn't matter to you whether you are right or 180 degrees off."
}

The search for an explanation the way the world works can easily be substituted by a search for fame, period. The difficulty with using citation statistics is that this distinction is lost in the translation and the strategies which deans and policy makers design. In that respect, being uncited is not necessarily a sign of waste just like receiving many citations is not necessarily a sign of a scientific breakthrough. It could be more heat than light. If citation studies are to shed light on the practice of economists then at least the following two strategies may be worth considering.

Dig deeper...

Plain citation data can be just as misleading as macroeconomics statistics can tell you the state of a nation. Micro-studies and/or longitudinal data have to supplement the quest for the real waste. For instance, the Laband and Tollison (2003) study, just like the Science study of 1991 
uses a five-year period to evaluate the state of 'waste'. However, there are numerous studies which show that each discipline has a different lag structure with which ideas are acknowledged and cited (see Hargens, 2000). Furthermore, as Van Dalen and Henkens (2004) show the state of uncitedness is not necessarily a good predictor of future uncitedness. In other words, negative duration dependence in being cited is not some iron-clad rule.

To give another example, the age of rational expectations yielded a host of neutrality theorems of which the Ricardian equivalence theorem of Robert Barro is perhaps one of the most notable statements of this era in the history of economic thought. Figure 3 shows how the classical JPE paper on stating the neutrality of public debt has fared over the years.

Figure 3: Citations to the Ricardian equivalence paper of Barro (JPE, 1974)

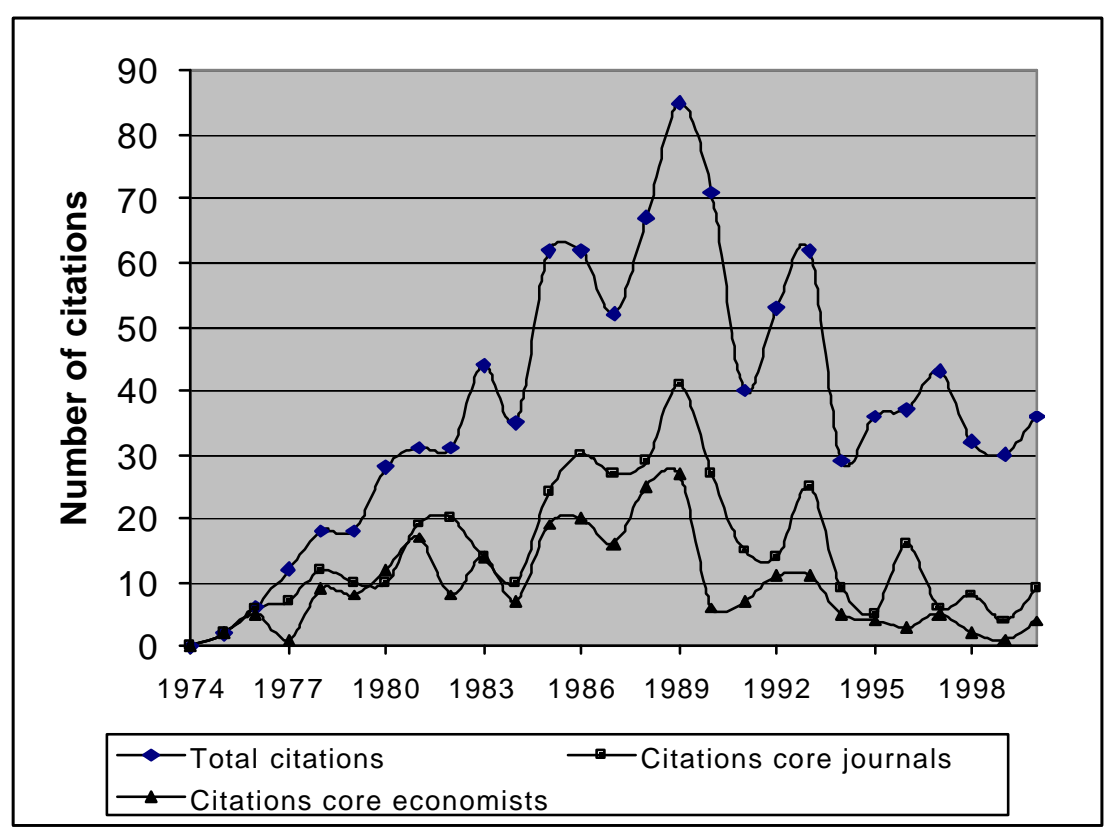

The 1980s were in that respect the high tide; right now the paper is getting citations from by and large second and third tier authors. The scientists working on the frontiers of knowledge are not that much affected by the Barro-paper. Perhaps this last phenomenon is not that exceptional. 'Obliteration by incorporation' is the Mertonian phrase and contributions can become so fundamental that only meticulous rookies take the pains to cite 'path-breaking' contributions. However, one can have serious doubts about the 'obliteration by incorporation' argument just by looking at three other fundamental papers written about the same time as Barro's classic: the paper by Peter Diamond on Public Debt (1965) -comparable in nature, 
subject and tone to that of Barro - the Dixit-Stiglitz paper on monopolistic competition (1977), and the Lemons paper by George Akerlof (see figures 4a-4c). Each of these papers displays perhaps the same citation pattern with respect to citations received in core journals or core economists (most core economists have lost interest in this issue), but the patterns diverge when it comes to the total number of citations. Where the influence of Barro's paper is clearly declining, the other papers display a steady and increasing citation rate. Apparently, their contribution is so fundamental that it still inspires many economists or is an essential 'stepping stone' in gaining insights.

Figure 4a: Citations to the Adverse Selection Paper of Akerlof (QJE, 1970)

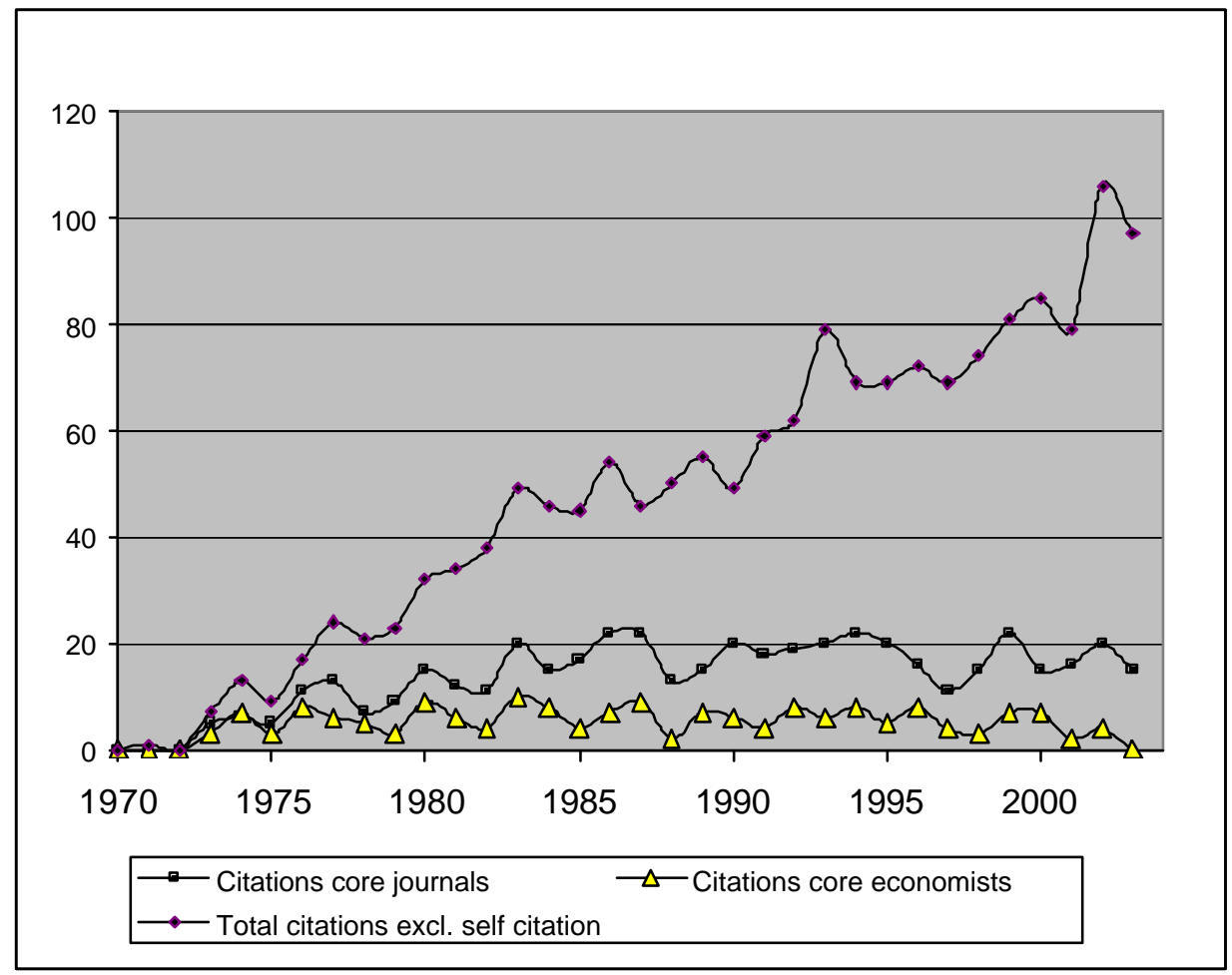


Figure 4b: Citations to the Dixit-Stiglitz Paper on Monopolistic Competition (AER, 1977)

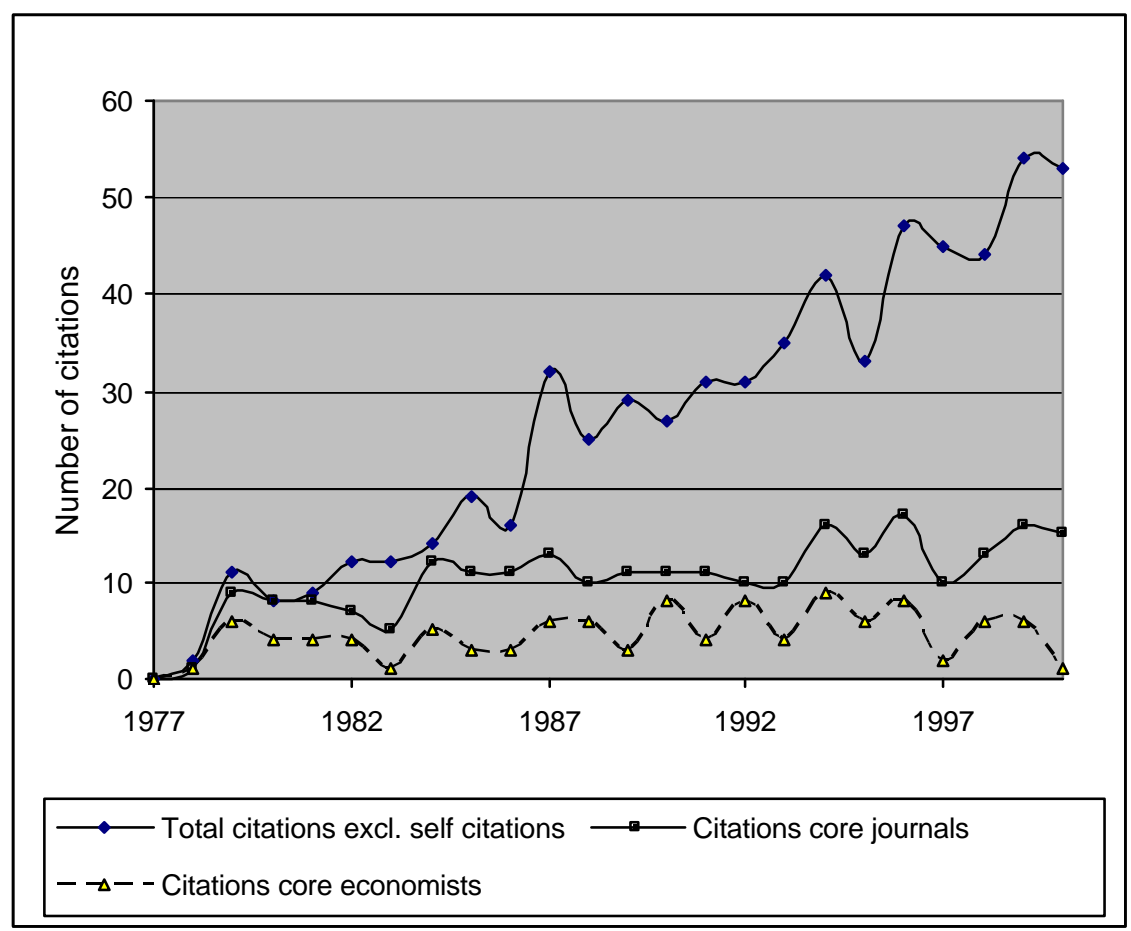

Figure 4c: Citations to the Paper on Public Debt and Growth by Diamond (AER, 1965)

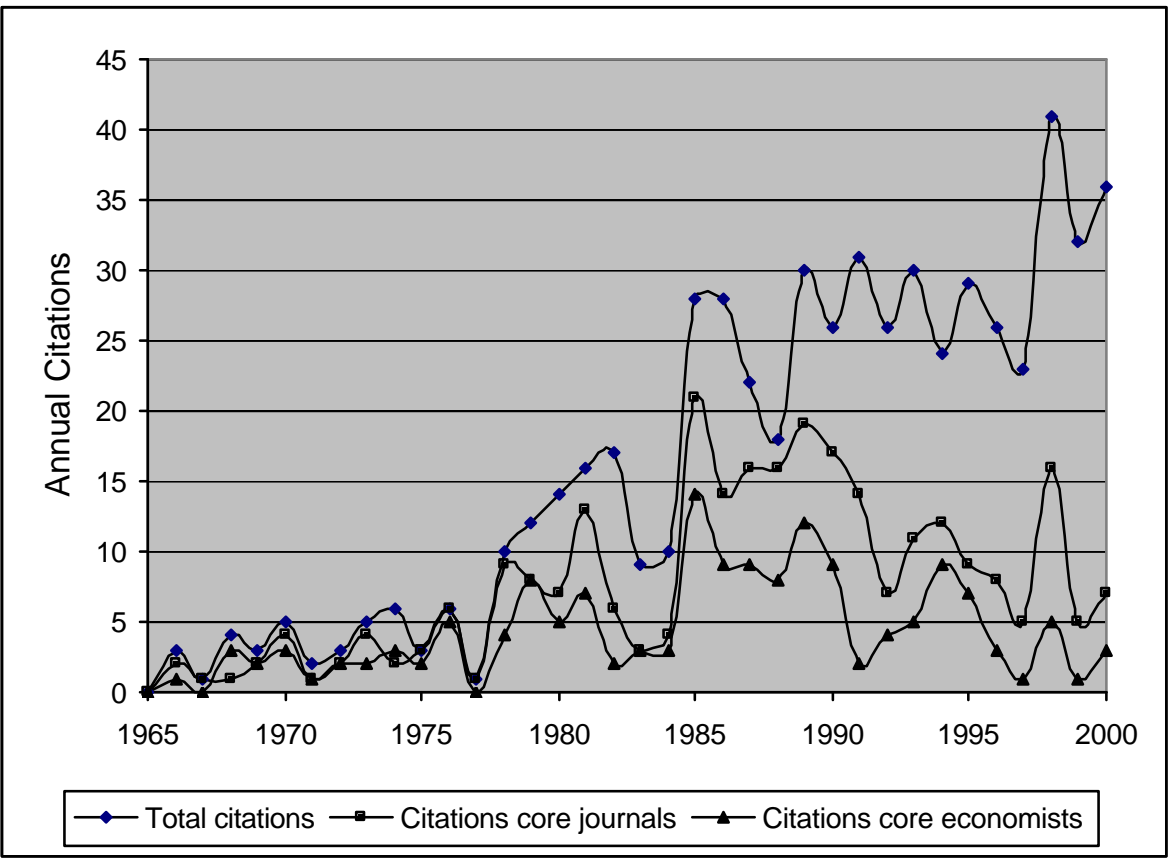


Another example of a problem of 'waste' that may be examined by digging deeper is the problem of plagiarism. The darker sides of the publish or perish culture become visible once scientists are tempted to perform fraudulent acts (like copying research, faking data and statistics, intentionally leaving out erroneous findings) or fall prone to unethical behaviour that is permitted by peers because the form of conduct has become 'normal'. Examples of the latter are reflected in citation games like not citing the 'enemy', the citation of friends and not giving credit when credit is due. But it is also apparent in publication strategies like slicing up one research in a number of more or less identical papers (the so-called salami tactics) which are submitted simultaneously to journals and edited books, putting your name on the list of authors (preferably first) without having contributed, leaving out authors (usually assistants or $\mathrm{PhD}$ students) in the list of contributors who have made a real contribution, etc. ${ }^{6}$ List et al. (2001) provide a peak into unethical behavior. They found a significant amount of misconduct among economists, particularly with respect to the expropriation of graduate student research or including an undeserving co-author on a research paper.

\section{... and look out of your window}

Another strategy which may supplement the information content of statistics and inform policy makers and practitioners to look out of your window and get to know the real world. Economists, taking their cue from Milton Friedman's influential essay on positive economics, are not enthused about asking their economic agents what goes on inside their black box. One should judge an agent by his actions not by his words is the tacit message economists bring across. Preferences do not have to be stated, they will reveal themselves by the deeds of agents. The funny thing is that the corner stone of every economist - the benefits of the division of labour - was explained by way of recounting the organisation of a pin factory. Adam Smith, or - closer to the truth - his teacher Francis Hutcheson who already used the example of the pin factory, discovered the use of reality economics. Economists are not very interested in their own pin factories and yet it is there that we can really get a feel for what 'productivity' and 'technical progress' really is, how it is brought about and how it is destroyed. Reality economics or 'learning by asking', as Alan Blinder et al. practice in their book Asking about Prices (1998) seems to be going through a revival. Of course, there have always been economists of name and fame who have always practised this art. Alfred Chandler and Ronald Coase are economists that can serve as role models. The basic idea of

\footnotetext{
${ }^{6}$ Hamermesh (1992) provides the young professional with some sound rules of conduct.
} 
reality economics, as we would like to call it, is that it not only offers a source of inspiration but primarily a reality check on the way scientific discovery works. 'Reality economics' as practiced through interviews and surveys may bring more to life what is going on inside a science than plain citation or publication statistics. In a series of interviews among economists we (Klamer, 1984, Klamer and Colander, 1990, and Van Dalen en Klamer, 1996) have sketched a picture of how the world of economists functions, what triggers their curiosity, who they respect, what they think makes an economist and what constitutes a persuasive argument. This type of research may help to focus on the essential questions which scholars face or why the distance between academia and the policy arena diverges by time or by culture.

\section{Conclusion and Discussion}

Contrary what is often believed, science is on the face of it not a game of wasteful competition. Based on statistics alone it is hard to say that public expenditure is being squandered, even if most of the research gone goes unnoticed. Our back-of-the-envelope calculations suggest that on a global scale the scientific publication industry costs the world 0.0006 percent of global income. In science and research and development so-called 'waste' or uncited patents and articles are part and parcel of the act of discovery. For practicing scientists this harsh 'fact of life' means concretely a scarcity of attention. The chance of catching the attention for your work is slim. The game of attention is unfair as only a few get the lion share of all attention. The winner in this game takes almost all.

However, our message is mixed: there may be 'waste' but citation and publication statistics are simply scratching at the surface. Exercises such as those of Laband and Tollison (2003) trigger a discussion but the figures they present are not conclusive. Like nineteenth century economist Frederic Bastiat was wont to stress: economists should try to "see what is not seen". We see a skewed distribution of attention but what lurks behind these citation statistics? The so-called 'waste' is not the main worry as it may be the very proof of healthy competition and the 'carrot' for inspiring scholars may be bigger than ever. "An information rich world creates a scarcity of attention", were the words of Herbert Simon (1971) and his observation was right on the mark. The more worrisome features of competition in academic economics reveal themselves not through ordinary statistics or the competitive attention seeking strategies, but the badly designed use of market principles in which citation statistics have become the measuring rod in evaluating and rewarding effort in science. Reward schedules in economic science fall prone to the classic problem of incentive design: 
rewarding A (publication) while hoping for B (novel ideas) or badly designed distribution of property rights of ideas (Frey, 2003). Perhaps at this point academia should pay close attention to how industry deals with innovation. One of the strategies to deal with the innovation in winner-take-all markets is to experiment and let a thousand flowers bloom. As Scherer and Harhoff (2000) point out for a world of highly skew-distributed outcomes: research programs should not be judged by the numerous failures, but the relatively few big successes should be emphasized.

\section{REFERENCES}

Blinder, A.S., E.R.D. Canetti, D.E. Lebow, and J.B. Rudd, 1998, Asking about Prices: A New Approach to Understanding Price Stickiness, Russell Sage Foundation.

Buchmüller, T.C., J. Dominitz and W.L. Hansen, 1999, Graduate Training and the Early Career Productivity of Ph.D. Economists, Economics of Education Review, 14: 65-77.

Cohen, J., 1999, The March of Paradigms, Science, 283: 1998-1999.

Crane, D., 1972, Invisible Colleges - Diffusion of Knowledge in Scientific Communities, University of Chicago Press, Chicago.

Ellison, G., 2002a, The Slowdown of the Economics Publishing Process, Journal of Political Economy, 110: 947-960.

Ellison, G., 2002b, Evolving Standards for Academic Publishing: A q-r Theory, Journal of Political Economy, 110: 994-1034.

Frank, R.H., and P.J. Cook, 1995, The Winner-Take-All Society, Penguin Books, New York.

Frey, B.S., 2003, Publishing as Prostitution? - Choosing Between One's Own Ideas and Academic Success, Public Choice, 116: 205-223.

Hamermesh, D.S., 1992, The Young Economist's Guide to Professional Etiquette, Journal of Economic Perspectives, 6: 169-179.

Hamilton, D.P., 1990, Publishing by - and for? - The Numbers, Science, 250: 1331-1332

Hamilton, D.P., 1991, Research Papers: Who's Uncited Now?, Science, 251: 25.

Hargens, L.L., 2000, Using the Literature: Reference Networks, Reference Contexts, and the Social Structure of Scholarship, American Sociological Review, 65: 846-865.

Hargens, L.L., and Schuman, H., 1990, Citation Counts and Social Comparisons: Scientists' Use and Evaluation of Citation Index Data, Social Science Research 19: 205-221. 
King, D.W., and C. Tenopir, 1998, Economic Cost Models of Scientific Scholarly Journals, Paper presented to the ICSU Press Workshop, Keble College, Oxford.

Klamer, A., 1984, The New Classical Macroeconomics - Conversations with New Classical Economists and their Opponents, Harvester Press, Brighton.

Klamer, A., and D. Colander, 1990, The Making of an Economist, Boulder: Westview Press.

Klamer, A. and H.P. van Dalen, 2002, Attention and the Art of Scientific Publishing, Journal of Economic Methodology, 9: 289-315.

Laband, D.N., and R.D. Tollison, 2003, Dry Holes in Economic Research, Kyklos, 56: 161174.

Leamer, E., 1981, The Hit Parade of Economic Articles, Comparative Economic Systems, 14: 3-54.

List, J.A., C.D. Bailey, P.J. Euzent, and T.L. Martin, 2001, Academic Economists Behaving Badly? A Survey on Three Areas of Unethical Behavior, Economic Inquiry, 39: 162170.

Lucas, R.E., Jr., 2001, Professional Memoir, mimeo, University of Chicago.

Mayer, T., 2004, Dry Holes in Economic Research - Comment, Kyklos, 57: 621-626.

Merton, R.K., 1968, The Matthew Effect in Science, Science 159: 56-63.

Merton, R.K., 1988, The Matthew Effect in Science II: Cumulative Advantage and the Symbolism of Intellectual Property, ISIS, 79: 606-623.

Odlyzko, A., 1997, The Economics of Electronic Journals, First Monday, http:// www.press.umich.edu/jep/04-01/odlyzko.html;

Rosen, S., 1981, The Economics of Superstars, American Economic Review, 71: 845-585.

Scherer, F.M., and D. Harhoff, 2000, Technology Policy for a World of Skew-Distributed Outcomes, Research Policy, 29: 559-566.

Simon, H.A., 1971, Designing Organizations for an Information-Rich World, in: M.

Greenberger (ed.), Computers, Communication and the Public Interest, Johns Hopkins University, Baltimore, pp. 37-52.

Stigler, G.J., 1955, The Nature and Role of Originality in Scientific Progress, in: G.J. Stigler, 1965, Essays in the History of Economics, University of Chicago Press, Chicago.

Stigler, G.J., S.M. Stigler, and C. Friedland, 1995, The Journals of Economics, Journal of Political Economy, 103: 331-359.

Stiglitz, J.E., 1999, Knowledge as a Global Public Good, in: I. Kaul, I. Grunberg, and M.A. Stern (eds.), Global Public Goods, Oxford. 
Tenopir, C. and D.W. King, 1998, Designing Electronic Journals with 30 years of Lessons from Print, Journal of Electronic Publishing, 4, http://www.press.umich.edu/jep/04$\underline{02 / \text { king.html }}$

Van Dalen, H.P., 1999, The Golden Age of Nobel Economists, The American Economist, 43: 19-35.

Van Dalen, H.P. and K. Henkens, 2004, Signals in Science - On the Importance of Signaling in Gaining Attention in Science, TI Discussion paper, Rotterdam, www.tinbergen.nl.

Van Dalen, H.P. and A. Klamer, 1996, Telgen van Tinbergen - Het verhaal van de Nederlandse economen ('The Heirs of Tinbergen'), Balans, Amsterdam.

Van Ours, J.C., and G. Ridder, 2003, Fast Track or Failure: A Study of the Graduation or Dropout Rates of PhD Students in Economics, Economics of Education Review, 22: 157-166.

Zuckerman, H., 1977, The Scientific Elite - Nobel Laureates in the United States. New York: Free Press. 